\title{
Manipulative Synthesis of Multipod-Frameworks for Self-Organization and Self-Amplification of $\mathrm{Cu}_{2} \mathrm{O}$ Microcrystals
}

\author{
Yu Chang and Hua Chun Zeng* \\ Department of Chemical and Environmental Engineering, Faculty of Engineering \\ National University of Singapore, 10 Kent Ridge Crescent, Singapore 119260
}

\section{Representative XRD patterns of synthesized $\mathrm{Cu}_{2} \mathrm{O}$ samples:}

The following XRD patterns ( $\mathrm{S} 5$ to $\mathrm{S} 34$ are sample numbers) were collected from $\mathrm{Cu}_{2} \mathrm{O}$ samples with different branching crystal morphologies (see main text for further information). S5 = Figure 2c,d; S7 = Figure 3a-d; S9 = hexa-pods (type (iv)); S15 = hexa-pods (type (iv)); S25 = Figure 5; S31 = Figure 2a,b; S32 = Figure 3e,f; S34 = hexa-pods (type (iv)). Note that there are variations in the reflection peak intensity, and the relative intensities of the reflection peaks are indeed proportional to the crystallographic planes observed in the samples (see the main text).

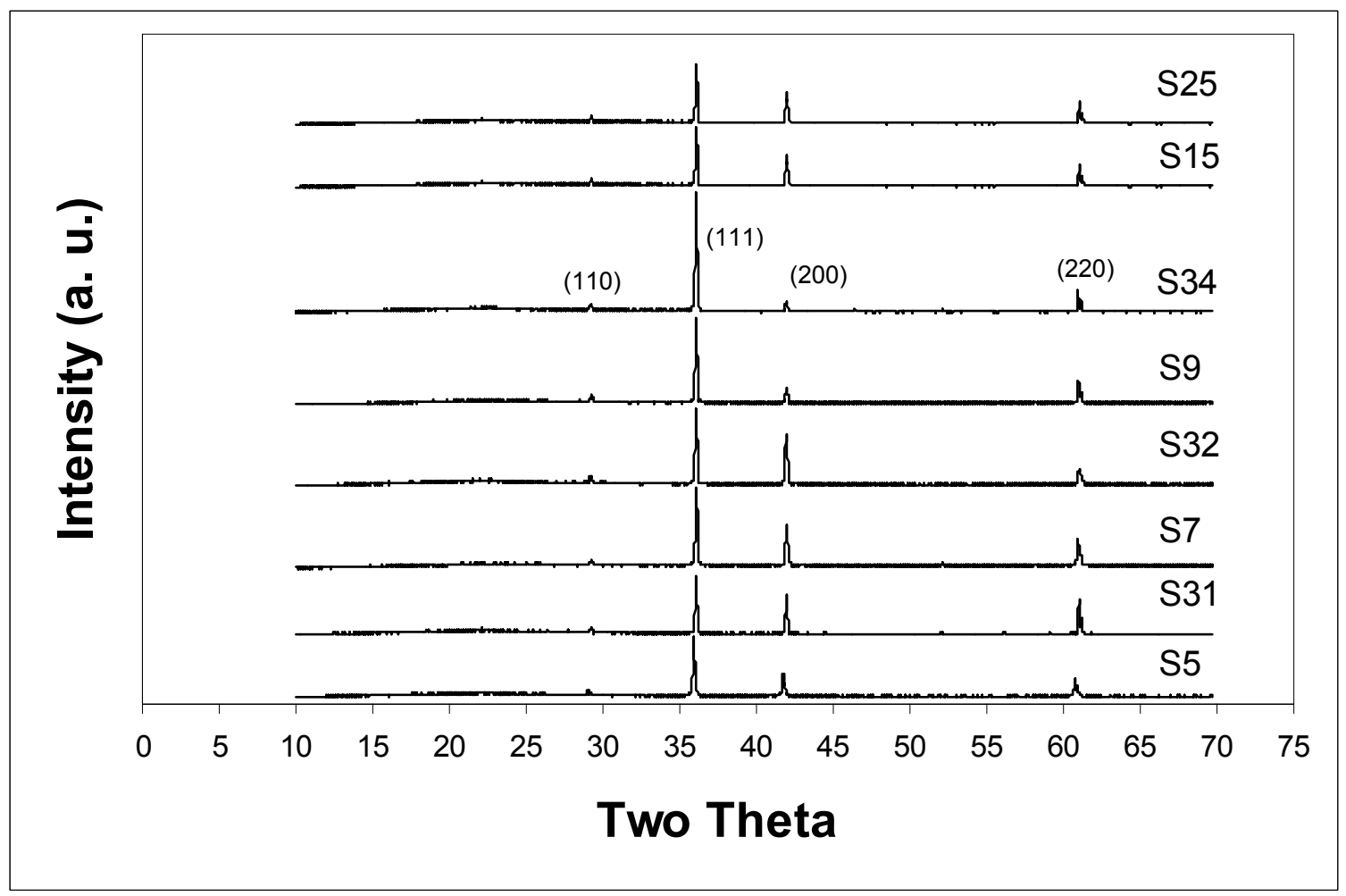


The following two SEM images were taken for $\mathrm{Cu}_{2} \mathrm{O}$ cubes synthesized without adding water in the starting solution (see main text).
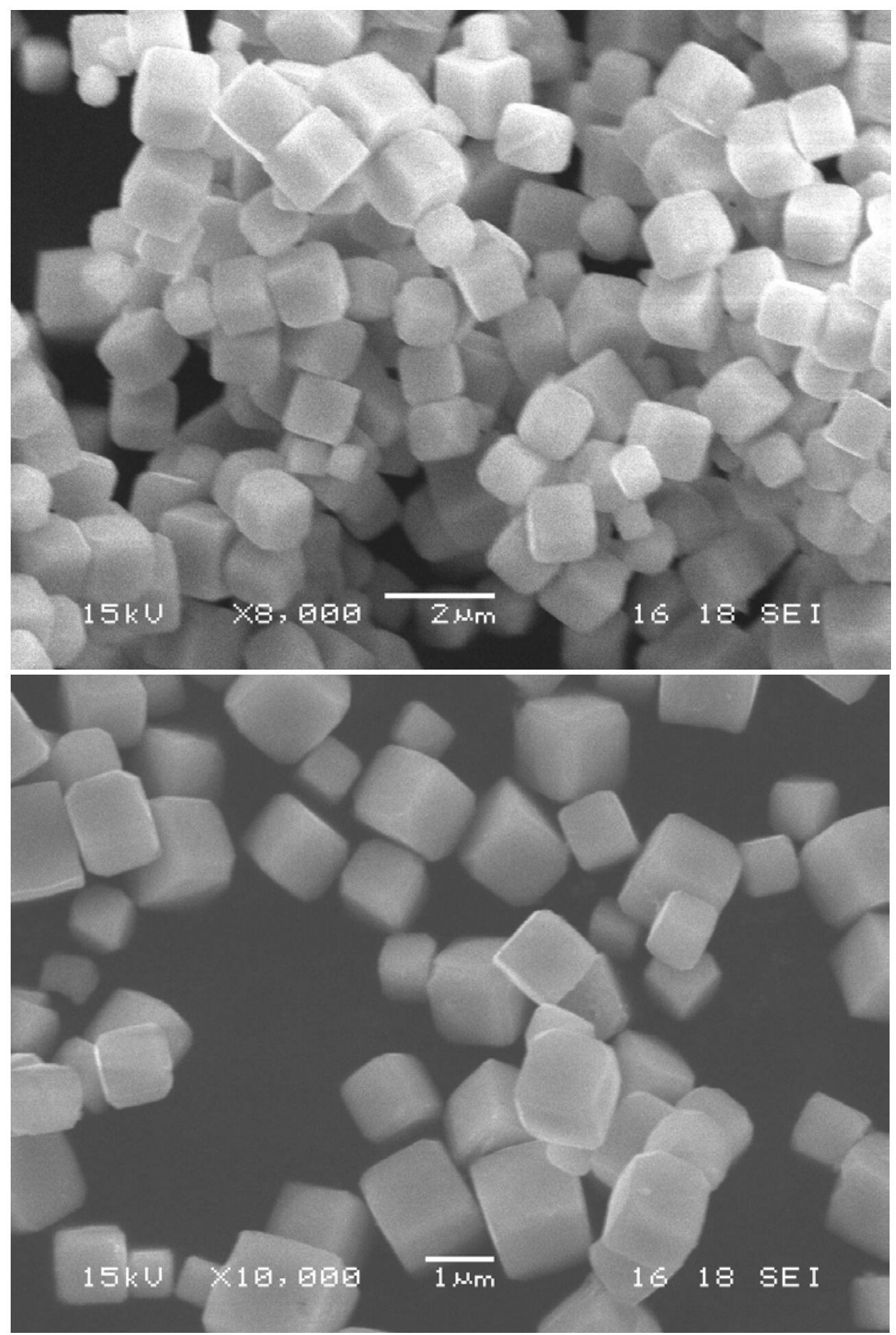